\title{
Association of lean body mass to menopausal symptoms: The Study of Women's Health Across the Nation
}

\author{
Rosanne Woods ${ }^{*}$ iD, Rebecca Hess, Carol Biddington and Marc Federico
}

\begin{abstract}
Background: The purpose of this study was to examine the association of lean body mass (LBM) to the development of vasomotor symptoms (VMS) as women transition through menopause.

Methods: This study is a secondary use of data available for public use from follow up visits six through 10 for participants in the Study of Women's Health Across the Nation. The study examined 2533 women, between the ages 42-52 years, each year over a10-year period. Data was modeled for associations of lean body mass and VMS. Changes in LBM since prior visit and since baseline were also modeled along with differences in means using binary logistic regression, adjusting for covariates.

Results: LBM was significantly associated to concurrent VMS $(p=.036)$, percent change in LBM since prior visit $(p=.003)$, percent change since baseline $(p<.001)$, and overall means associations $(p=.023)$. LBM was not significant for VMS at individual visit measures. In mixed regression modeling, time was significant $(p<.0001)$ at all visits. The estimated probability of developing VMS decreases significantly as LBM increases.

Conclusions: Lean body mass is negatively associated with incident VMS. Our data suggests that maintaining higher levels of LBM during the menopausal transition may be protective against the development of VMS. Every woman will experience menopause in her life and the ability to potentially prevent the onset of specific symptoms through basic interventions, such as resistance training to increase lean body mass, may positively impact this large population.
\end{abstract}

Keywords: Lean body mass, Vasomotor symptoms, Hot flashes, Menopause - women

\section{Introduction}

Menopause is a significant event in many women's lives as it marks the end of the natural reproductive life. For most women, menopause will occur between the ages of 40 and 58 years with the average being 51 years [1]. About $80-96 \%$ of women experience mild to severe physical or physiological menopause-related complaints as they approach menopause due to declining estrogen levels [2]. Symptoms may include hot flashes and night

\footnotetext{
* Correspondence: rosannewoods7@gmail.com

Department of Exercise Science and Sport Studies, California University of Pennsylvania, 50 University Ave, California, PA 15419, USA
}

sweats, depression, irritability, sleep disorders, increased abdominal fat mass, increased prevalence of metabolic syndrome, and increased risk of cardiovascular disease [3]. Hot flashes and night sweats are the most common symptoms of menopause and are collectively referred to as vasomotor symptoms (VMS). It is reported that 60 $80 \%$ of women will experience VMS at some point during the menopausal transition [4].

As they transition through menopause, women will simultaneously experience a decrease in basal metabolic rate and a loss of lean muscle tissue which increases the risk of weight gain and obesity [5]. Sarcopenia develops

(C) The Author(s). 2020 Open Access This article is licensed under a Creative Commons Attribution 4.0 International License, which permits use, sharing, adaptation, distribution and reproduction in any medium or format, as long as you give appropriate credit to the original author(s) and the source, provide a link to the Creative Commons licence, and indicate if changes were made. The images or other third party material in this article are included in the article's Creative Commons licence, unless indicated otherwise in a credit line to the material. If material is not included in the article's Creative Commons licence and your intended use is not permitted by statutory regulation or exceeds the permitted use, you will need to obtain permission directly from the copyright holder. To view a copy of this licence, visit http://creativecommons.org/licenses/by/4.0/ The Creative Commons Public Domain Dedication waiver (http://creativecommons.org/publicdomain/zero/1.0/) applies to the data made available in this article, unless otherwise stated in a credit line to the data. 
and is highly prevalent during menopause and is primarily due to an imbalance between muscle protein synthesis and breakdown, contributed to by an increase in oxidative stress, pro-inflammation markers, and hormonal changes [6]. Evidence indicates that muscle strength and quality (ratio of muscle strength to mass) may be negatively associated with the severity of menopausal symptoms due to declining levels of sex hormones and the resulting increase in oxidative stress [7]. Postmenopausal women have been shown to have significantly higher oxidative stress blood marker levels and lower antioxidant capacity relative to premenopausal women [8].

For postmenopausal women, chronic systemic inflammation, oxidative stress, abdominal visceral adipose tissue, dyslipidemia, sarcopenia, and a sedentary lifestyle are all risk factors for metabolic syndrome [9]. A systematic review found that the menopausal transition is associated with a decline in estrogen, growth hormone, insulin-like growth factor (IGF-1), and dehydroepiandrosterone (DHEA), a decrease in muscle protein synthesis, and an increase in catabolic factors such as the pro-inflammatory cytokines, and tumor necrosis factor alpha (TNF- $\mathbf{\alpha}$ ) or interleukine 6 (IL-6) [10]. A recent study found that weight-adjusted lean body mass (LBM) and skeletal muscle area were protective against weightassociated insulin resistance and metabolic abnormalities [11] suggesting that women with lower muscle mass and fewer estrogen receptors are therefore at greater risk for metabolic complications [12]. Decreased LBM has been found to be the most important contributor to changes in metabolism for postmenopausal women as it correlates to low whole-body fat oxidation and energy expenditure which in turn are associated with high visceral fat mass and low insulin resistance [13]. Maintaining adequate levels of muscle mass as women transition into menopause may play a role in minimizing the risks of sarcopenic obesity and protect against the development of deleterious metabolic conditions commonly associated with menopause. However, little is known regarding the role of LBM and its influence on menopausal symptoms throughout the transition period. The following hypotheses were examined: Hypothesis $1\left(\mathrm{H}_{1}\right)$ - Lower concurrent LBM will be associated with greater concurrent incident reporting of VMS; Hypothesis $2\left(\mathrm{H}_{2}\right)$ - In longitudinal analyses, lower LBM over time, since baseline, will be associated with greater incident reporting of VMS; Hypothesis $3\left(\mathrm{H}_{3}\right)$ - In longitudinal analyses, lower LBM over time, since last annual visit, will be associated with greater incident reporting of VMS.

\section{Methods}

This study was a secondary analysis of existing data utilizing the public dataset from the SWAN study [14-19].
Details of the SWAN design and recruitment procedures are reported elsewhere [20], however, a brief summary is provided here. Baseline eligibility criteria included being aged 42 to 52 years, having a uterus and at least one ovary, not being pregnant or lactating, not using oral contraceptives or hormone therapy in the previous 3 months, and having at least one menstrual cycle in the preceding months. Participants self-identified as AfricanAmerican (28\%), Caucasian (47\%), Chinese (8\%), Hispanic $(8 \%)$, or Japanese (9\%). Eligible women meeting the inclusion criteria were invited to join the cohort and were seen within 3 months of the initial survey for their baseline assessment where a written informed consent was obtained. Assessments consisted of questionnaires regarding medical history, medication, menstrual history, lifestyle, psycho-social factors, physical and psychological symptoms, and health-related quality of life, as well as blood and urine specimen collection and physical measures. Procedures specific to this study included annual examinations, questionnaires, and bioelectrical impedance analysis measures. Approval for this study was granted by the Institutional Review Board at California University of Pennsylvania.

\section{Anthropometry/body composition}

Analysis was limited to the use of body composition data collected using BIA and included 2533 women. BIA is based on measurement of the transmission speed of a one-quarter volt electrical pulse between electrodes attached at the feet and electrodes attached across the knuckles of the hand. Because fat-free mass is comprised of water, proteins, and electrolytes, conductivity is greater in fat-free mass than in fat mass [21]. Resistance and reactance are used to estimate total body water, and by extension, fat mass and lean mass, with the latter including bone [22]. The validity and predictive value of BIA in menopausal women has been confirmed by a recent study [23]. Skeletal muscle mass was calculated by the method of Janssen et al. [24], who subsequently indexed skeletal muscle mass to height for a skeletal muscle index $(\mathrm{SMI}=$ skeletal muscle mass $(\mathrm{kg}) /$ height $\left(\mathrm{m}^{2}\right)$ ). For the purposes of this study, LBM refers to the level of skeletal muscle mass and will be represented by the variable SMI. Fat free mass, total body water, and percent body fat were all provided by RJL Systems and validated using NHANES III data [25]. Fat free mass $(\mathrm{kg})$ and fat mass $(\mathrm{kg})$ were both indexed to height to create fat mass index $\left(\mathrm{FMI}=\mathrm{kg} / \mathrm{m}^{2}\right)$ and fat free mass index $\left(F F M I=\mathrm{kg} / \mathrm{m}^{2}\right)$. Height $(\mathrm{m})$ and weight $(\mathrm{kg})$ were measured in light clothing, without shoes, using a standard protocol with a stadiometer for height and a balance beam scale for weight. Hip circumference $(\mathrm{cm})$ was measured at the iliac crest and waist circumference $(\mathrm{cm})$ was 
measured at the level of the natural waist or the narrowest part of the torso from the anterior aspect $[26,27]$.

\section{Vasomotor symptoms}

Hot flashes and night sweats were assessed via questionnaire at each SWAN visit. Women responded to two questions that separately asked them to record how often hot flashes and night sweats were experienced in the 2 weeks prior to the annual visit (not at all, 1-5 days, 6-8 days, 9-13 days, everyday). Accuracy of recall for VMS among the SWAN participants was previously verified [28].

\section{Covariates}

Covariates were selected on the basis of previously documented associations with VMS [29] and body composition [27], and included age, educational level (less than high school, high school, some college, college, or post baccalaureate degree), race/ethnicity, quality of life, and menopausal transition stage. Race/ethnicity and educational level were self-reported in the SWAN screening interview. SWAN participants were assessed for menopausal status assignment based on annual reports about menstrual bleeding and its regularity. Pre-menopause was identified as no decreased regularity in menstrual bleeding during the last year. Other classifications were early perimenopause (decreased menses in previous 3 months), late perimenopause (no menses for 3-11 months), and postmenopause (no menses for $12+$ months) [30]. Surgical menopause was defined by report of either hysterectomy or oophorectomy, and hormone therapy (HT) use was reported as use of HT during the year [30]. The Medical Outcomes Short-Form 36 (SF36) was used to assess health related quality of life (HRQL) using the original coding algorithm in which raw scores are transformed to a 0 to 100 range.

\section{Statistical analysis}

Characteristics of the sample were described by means (standard deviation) and frequency (\%). At baseline, two VMS groups - any or none - were compared for group differences in, and associations among, demographics (age, race/ethnicity, education), quality of life (SF-36 score), and clinical characteristics (weight, hip and waist circumference, menopausal status, fat mass, fat free mass, skeletal mass), and VMS was estimated using chi square test $\left(x^{2}\right)$ for categorical variables, and KruskalWallis test for continuous variables. A scatter plot matrix was used to examine linear correlations among variables. For the purposes of modelling, LBM is represented by the SMI variable. Additionally, to account for the nonindependence of longitudinal observations derived from the same woman and data in which the number of observations may differ across women, longitudinal modeling using SAS PROC MIXED incorporated a random intercept term to account for the correlated errors among repeated measures of the same woman. Missing values of time-varying variables were interpolated based on prior and subsequent values for gaps of one to two visits as in previous SWAN analyses [31]. To assess $\mathrm{H}_{1}$, incident VMS was modeled as a function of concurrent LBM using logistic regression analysis. To address $\mathrm{H}_{2}$ regarding long term change in LBM, the model was expanded to add within-woman percent change in LBM since baseline and to address $\mathrm{H}_{3}$, regarding recent change in LBM, the model was expanded to add within-woman percent change in LBM since prior visit (approximately 1 year earlier). The overall association between LBM and VMS was estimated in binary logistic regression models. Statistical analyses were one-tailed with an alpha level of 0.05 and conducted using SAS University Edition (ㄷ 2012-2018, SAS Institute Inc., Cary, NC).

\section{Results}

At baseline (visit 6) there were 2533 participants remaining in the SWAN study who were on average 52 years old and the differences in the group characteristics are shown in Table 1 . Only women reporting no symptoms at baseline $(n=1179)$ were included in longitudinal analyses for VMS with LBM. At visit 10 there were 800 women remaining in the study.

At baseline, SMI showed a strong positive correlation to FFMI both for symptoms = none $\left(r_{0} \quad(864)=0.931\right.$, $p<.0001)$ and symptoms $=$ any $\quad\left(\mathrm{r}_{1} \quad(1143)=0.933\right.$, $p<.0001)$, and a moderate positive correlation to FMI $\left(\mathrm{r}_{0}(864)=0.567, p<.0001\right)\left(\mathrm{r}_{1}(1143)=0.579, p<.0001\right)$. FMI showed a strong positive correlation to FFMI at baseline for both groups $\left(\mathrm{r}_{0}(864)=0.820, p<.0001 ; \mathrm{r}_{1}\right.$ $(1143)=0.826, p<.0001)$. Pearson correlation of mean SMI to mean FMI (calculated on a participant basis over visits $6-10)$ was moderately strong for 'none' $\left(\mathrm{r}_{0}(405)=\right.$ $0.648, p<.0001)$ and relatively weak for 'any' with $\left(\mathrm{r}_{1}\right.$ $(611)=0.559, p<.0001)$. Mean FFMI was strongly correlated to mean FMI in both groups $\left(\mathrm{r}_{0}(405)=0.860\right.$, $\left.p<.0001 ; \mathrm{r}_{1}(611)=0.829, p<.0001\right)$. Mean SMI was very strongly correlated to both symptom groups for mean FFMI $\left(\mathrm{r}_{0}(405)=0.942, p<.0001 ; \mathrm{r}_{1}(611)=0.923\right.$, $p<.0001)$. SMI continued to be very strong as expected and the relationship of FFMI to FMI remained consistent over time.

Models were developed to address the three hypotheses and are presented as odds ratios and 95\% confidence intervals for incident VMS in Table 2. Adjusted models included time-varying covariates of FMI, age, and menopausal status and single-time variates of race/ ethnicity and education. Quality of life scores were not significant in any models and were not considered in 
Table 1 Baseline Characteristics by symptom status, SWAN

\begin{tabular}{|c|c|c|c|c|c|}
\hline & \multicolumn{5}{|c|}{ Presence of vasomotor symptoms (VMS) } \\
\hline & None & $(\% n)$ & Any & $(\% \mathrm{n})$ & $p$ \\
\hline$n$ & 1179 & $(47 \%)$ & 1354 & $(53 \%)$ & \\
\hline Age, yr (mean \pm ) & $52.0 \pm 2.7$ & & $52.0 \pm 2.6$ & & \\
\hline Race/Ethnicity (n) & & & & & $<.0001$ \\
\hline African American & 272 & $(36 \%)$ & 494 & $(64 \%)$ & \\
\hline Caucasian & 619 & $(50 \%)$ & 622 & $(50 \%)$ & \\
\hline Chinese & 118 & $(52 \%$ & 107 & $(48 \%)$ & \\
\hline Hispanic & 144 & $(54 \%)$ & 122 & $(46 \%)$ & \\
\hline Japanese & 26 & $(67 \% 0$ & 13 & $(33 \%)$ & \\
\hline Education $(n)$ & & & & & $<.0007$ \\
\hline$\leq$ High School & 225 & $(44 \%)$ & 286 & $(56 \%)$ & \\
\hline Some College & 349 & $(42 \%)$ & 481 & $(58 \%)$ & \\
\hline$\leq$ College Graduate & 595 & $(50 \%)$ & 584 & $(50 \%)$ & \\
\hline Menopausal Status $(n)$ & & & & & $<.0001$ \\
\hline Postmenopausal & 430 & $(42 \%)$ & 591 & $(58 \%)$ & \\
\hline Late Perimenopausal & 77 & $(32 \%)$ & 163 & $(68 \%)$ & \\
\hline Early Perimenopausal & 368 & $(50 \%)$ & 372 & $(50 \%)$ & \\
\hline Premenopausal & 54 & $(68 \%)$ & 26 & $(33 \%)$ & \\
\hline \multicolumn{6}{|l|}{ Body Composition (mean \pm SD) } \\
\hline Weight (kg) & $74.3 \pm 20.7$ & & $78.4 \pm 20.7$ & & $<.0001$ \\
\hline BMI $\left(\mathrm{kg} / \mathrm{m}^{2}\right)$ & $28.1 \pm 7.3$ & & $29.6 \pm 7.3$ & & $<.0001$ \\
\hline Body Fat (\%) & $36.8 \pm 8.0$ & & $39.1 \pm 7.6$ & & $<.0001$ \\
\hline Total Body Fat (kg) & $28.3 \pm 13.2$ & & $31.9 \pm 13.9$ & & $<.0001$ \\
\hline Fat Mass Index $\left(\mathrm{kg} / \mathrm{m}^{2}\right)$ & $10.75 \pm 4.9$ & & $12.03 \pm 5.11$ & & $<.0001$ \\
\hline Fat Free Mass (kg) & $45.1 \pm 7.4$ & & $46.3 \pm 7.6$ & & .0002 \\
\hline Fat Free Mass Index $\left(\mathrm{kg} / \mathrm{m}^{2}\right)$ & $17.1 \pm 2.4$ & & $17.5 \pm 2.5$ & & .0003 \\
\hline Skeletal Muscle Mass (kg) & $20.6 \pm 3.3$ & & $20.9 \pm 3.3$ & & .0423 \\
\hline Skeletal Muscle Index $\left(\mathrm{kg} / \mathrm{m}^{2}\right)$ & $7.8 \pm 1.1$ & & $7.9 \pm 1.1$ & & .1298 \\
\hline Waist Hip Ratio (\%) & $0.81 \pm 0.07$ & & $0.83 \pm 0.07$ & & $<.0001$ \\
\hline
\end{tabular}

Notes: SWAN Study of Women's Health Across the Nation, BMI Body mass index;

Table 2 Association of VMS to lean body mass (Odds Ratios)

\begin{tabular}{|c|c|c|c|c|c|c|}
\hline \multirow[b]{2}{*}{ SMI/FFMI } & \multicolumn{3}{|c|}{ Unadjusted } & \multicolumn{3}{|c|}{ Adjusted * } \\
\hline & $O R$ & $95 \% \mathrm{Cl}$ & $p$ & OR & $95 \% \mathrm{Cl}$ & $p$ \\
\hline Model $1^{a}$ & 0.54 & {$[0.43,0.68]$} & $<.0001$ & 0.93 & {$[0.87,0.99]$} & .036 \\
\hline Model $2^{b}$ & 0.15 & {$[0.05,0.41]$} & .001 & 0.12 & {$[0.04,0.33]$} & $<.001$ \\
\hline Model $3^{c}$ & 0.21 & {$[0.08,0.58]$} & .009 & 0.17 & {$[0.06,0.49]$} & .003 \\
\hline Model $4^{d}$ & 0.38 & {$[0.18,0.76]$} & .007 & 0.22 & {$[0.08,0.61]$} & .023 \\
\hline
\end{tabular}

Note: VMS Vasomotor symptoms, OR Odds ratio, Cl Confidence interval, LBM Lean body mass, SMI Skeletal muscle index, FFMI fat free mass index;

aMS with concurrent LBM

${ }^{\mathrm{b}}$ Model 1 plus \% change in SMI/FFMI since baseline

${ }^{c}$ Model 1 plus \% change in SMI/FFMI since prior visit

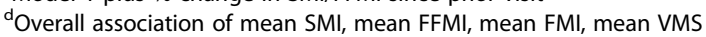

eAdjusted for covariates fat mass index, age, race/ethnicity, education,

menopausal status further analyses. For $\mathrm{H}_{1}$ (VMS associations with concurrent LBM) results are summarized in Model 1 where LBM is significant in both the unadjusted $(p<.0001)$ and adjusted $(p=.036)$ analyses. For $\mathrm{H}_{2}$ (VMS associations with LBM over time since baseline), within woman percentage change since baseline was added to Model 1 and results are presented as Model 2. Again, LBM showed significance in both unadjusted $(p=.001)$ and adjusted $(p<.001)$ modelling. For $\mathrm{H}_{3}$, (VMS associations with LBM over time since prior visit) within women percentage change since prior visit was added to Model 1 and the results are summarized as Model 3. LBM remained significant in unadjusted $(p=.009)$ and adjusted $(p=.003)$ models respectively.

FMI was significant in adjusted models 1 ( $p=.0003), 2$ $(p<.0001), 3 \quad(p<.0001)$, and $4 \quad(p=.0073)$. Race $/$ 
ethnicity was significant in Models $1(p<.0001)$ and 2 $(p=.0139)$ but failed to reach significance for Model 3 or 4. Menopausal status was significant $(p=.0052)$ in Model 4 only. Age was not significant in any model. In mixed regression models of VMS and LBM repeated for time (symptoms as random effect), results were significant $(p<.0001)$ for least squares means at visit (time) 6 , $7,8,9$, and 10 . Additionally, significance $(p<.0001)$ was found for the difference of least square means (TukeyKramer method) at visit 6 (time effect 6-7, 6-8, 6-9, 6$10)$, and for time effect visit 8-10 $(p=.007)$ (data not shown). Further, estimated predicted probabilities were examined to determine the likelihood of LBM to predict the development of VMS. The probabilities estimated for given levels of SMI at each of the four visits following baseline, including the mean over time, for women reporting no VMS at visit $6(n=1179)$ shows significant negative correlation to levels of SMI (Fig. 1).

\section{Discussion}

This study is among the first to examine the relationship of lean body mass to vasomotor symptoms longitudinally. Using the data for this large, multiethnic sample of mid-age women from the SWAN study, we found that participants with higher relative levels of LBM were less likely to develop VMS as they transitioned through menopause. This effect was found to be independent of sociodemographic factors and levels of fat mass. Additionally, as the average age of the participants in our study increased from 52.0 to 56.6 years and the number of women who were postmenopausal increased from $40 \%(n=430)$ at visit 6 to $72 \%(n=733)$ at visit 10 , our study was able to document the movement through menopausal transition for the majority of the cohort.

Considerable recent research has focused on the association of body mass index (BMI) and percent body fat with VMS and has suggested a positive correlation between increasing BMI and the presence of VMS [30, 3236]. However, BMI is considered a poor predictor of body mass as it is merely a measure of excess weight and does not distinguish between body fat mass and fat free mass [37]. Our study examined the components of body composition and found lean mass, determined by both fat free mass and skeletal muscle mass, to have a significant effect on the likelihood of developing VMS over time while still considering the potential impact of fat mass. A recent cross-sectional study of 758 women found that trunk lean mass was an independent protective factor for moderate to severe menopausal symptoms and that VMS were independently related to higher BMI and fat mass [38]. The underlying mechanisms of the relationship between body composition and VMS are not entirely clear due to the incomplete understanding of the physiology of VMS [2].

Evidence is emerging on the role of oxidative stress in menopause and its relationship to muscle mass. Lipoperoxide (LPO) levels are considered a measure of oxidative stress and in postmenopausal women are found to be significantly higher than in premenopausal women suggesting that the depletion of estrogen is a risk factor for oxidative stress [39]. A recent study showed that the loss of muscle mass in menopause, due to declining estrogen levels, was negatively associated with oxidative stress (LPO), but skeletal muscle mass was positively

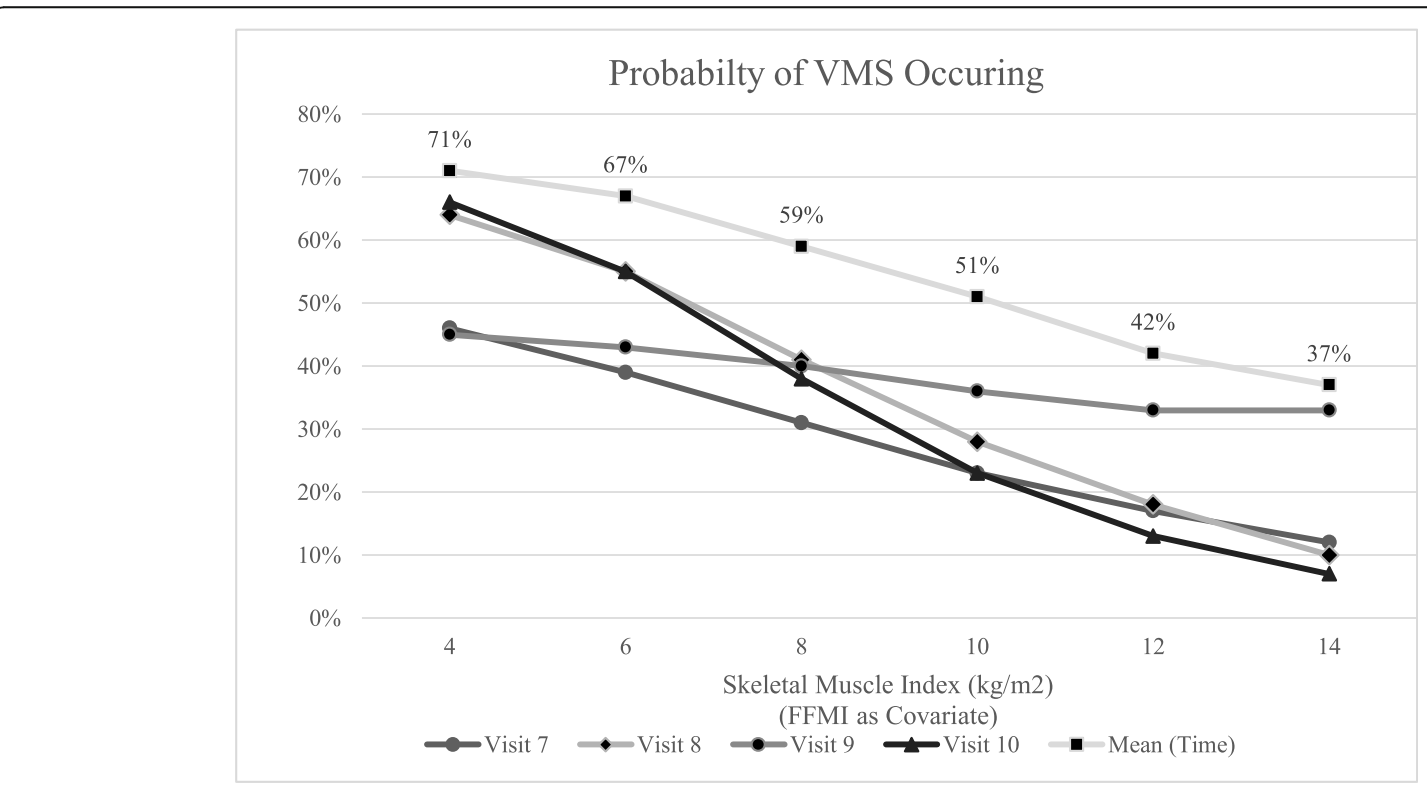

Fig. 1 Predicted probability of symptoms occurring at given levels of SMI (adjusted for FFMI and FMI) in women with no VMS at visit 6 (baseline) 
associated with serum uric acid which offers a protective role against oxidative stress due to its capacity to clear reactive oxygen species [40]. Increased oxidative stress has been found to also impair the ability of free oxygen radical defenses (FORD) in menopausal women, and that VMS are negatively associated with FORD [41]. Together, these results suggest that declining estrogen in menopause contributes to loss of muscle mass which simultaneously increases oxidative stress and decreases antioxidant levels potentially leading to higher probability of VMS. The results of our study add to the evidence that women with lower levels of LBM are more likely to experience VMS.

Certain limitations need consideration when interpreting results of the current study. The use of BIA measurement involves several assumptions, and while skeletal muscle mass was calculated using a validated equation by Janssen et al. [24] and fat mass and fat free mass were calculated with validated equations by Chumlea et al. [25], this allows for potentially differing interpretation of data supplied by the internal BIA system. Additionally, VMS were assessed through responses to two questions regarding number of days experiencing hot flashes or night sweats in the previous 2 weeks. This data yielded limited information and is subject to recall bias although this population was found to have high specificity and high sensitivity regarding VMS recall [28]. Moreover, odds ratios presented here should not be interpreted as measures of relative risk because VMS are not a rare outcome and the risk may be overestimated.

\section{Conclusion}

This study was among the first to examine the longitudinal association of LBM to VMS, providing new evidence that lean mass may provide protection against the development of VMS as women transition through menopause. Using the longitudinal SWAN database that encompasses a large, multiethnic sample of women from across the United States, these findings are particularly relevant and transferable to general populations in North America. Given the continued resistance to hormone replacement therapy as a means to mitigate symptoms, these results provide for the possibility of symptom prevention through resistance training programs. Importantly, the results of our study suggest that the greatest contributing factor to mitigating symptoms was maintaining LBM throughout the menopausal transition.

\section{Abbreviations}

BIA: Bioelectrical impedance analysis; BMI: Body mass index; FMl: Fat mass index; FFMI: Fat free mass index; FORD: Free oxygen radical defense; HRQL: Health related quality of life; HT: Hormone therapy; IGF-1: Insulin-like growth factor; IL-6: Interleukine 6; LBM: Lean body mass; LPO: Lipoperoxide; SMI: Skeletal muscle index; SWAN: Study of Women's Health Across the Nation; TNF-á: Tumor necrosis factor alpha; VMS: Vasomotor symptoms

\section{Acknowledgements}

Dr. Melissa Sovak, California University of Pennsylvania, for her contribution of expertise and supervision in statistical analyses.

\section{Authors' contributions}

RW analyzed and interpreted the data, $\mathrm{RH}, \mathrm{CB}$ and MF provided direction on statistical analysis, RW and $\mathrm{RH}$ were major contributors in writing the manuscript and all authors read and approved the final manuscript.

\section{Funding}

The authors received no funding for their work on this paper.

Availability of data and materials

The datasets used during the current study are available on the ICPSR repository https://www.icpsr.umich.edu/icpsrweb/ICPSR/series/00253 [14-19]

Ethics approval and consent to participate

This study was approved by the Institutional Review Board of California University of Pennsylvania (Proposal 17-022).

\section{Consent for publication}

Not applicable.

\section{Competing interests}

The authors declare that they have no competing interests.

Received: 13 January 2020 Accepted: 17 August 2020

Published online: 15 September 2020

\section{References}

1. Zapantis G, Santoro N. The menopausal transition: characteristics and management. Best Pract Res Clin Endocrinol Metab. 2003;17:33-52.

2. Moilanen JM, Aalto A-M, Raitanen J, Hemminki E, Aro AR, Luoto R. Physical activity and change in quality of life during menopause - an 8-year followup study. Health Qual Life Outcomes. 2012;10:8

3. Stefanska A, Bergmann K, Sypniewska G. Metabolic syndrome and menopause: pathophysiology, clinical and diagnostic significance. Adv Clin Chem. 2015;72:1-75

4. Thurston $\mathrm{RC}$, Joffe $\mathrm{H}$. Vasomotor symptoms and menopause: findings from the study of Women's health across the nation. Obstet Gynecol Clin N Am. 2011;38:489-501.

5. Lovejoy JC. Weight gain in women at midlife: the influence of menopause. Obes Manag. 2009;5:52-6.

6. Messier V, Rabasa-Lhoret R, Barbat-Artigas S, Elisha B, Karelis AD, AubertinLeheudre M. Menopause and sarcopenia: a potential role for sex hormones. Maturitas. 2011;68:331-6.

7. Lee J-Y, Lee D-C. Muscle strength and quality are associated with severity of menopausal symptoms in peri-and post-menopausal women. Maturitas. 2013;76:88-94.

8. Signorelli SS, Neri S, Sciacchitano S, Di Pino L, Pia Costa M, Marchese G, et al. Behavior of some indicators of oxidative stress in postmenopausal and fertile women. Maturitas. 2006;53:77-82

9. Mendoza N, Teresa C-D, Cano A, Godoy D, Hita-Contreras F, Lapotka M, et al. Benefits of physical exercise in postmenopausal women. Maturitas. 2016:93:83-8.

10. Maltais ML, Desroches J, Dionne IJ. Changes in muscle mass and strength after menopause. J Musculoskelet Neuronal Interact. 2009;9:186-97.

11. Takamura T, Kita Y, Nakagen M, Sakurai M, Isobe Y, Takeshita Y, et al. Weight-adjusted lean body mass and calf circumference are protective against obesity-associated insulin resistance and metabolic abnormalities. Heliyon. 2017;3:e00347.

12. Ou Y-C, Chuang H-H, Li W-C, Tzeng I-S, Chen J-Y. Gender difference in the association between lower muscle mass and metabolic syndrome independent of insulin resistance in a middle-aged and elderly Taiwanese population. Arch Gerontol Geriatr. 2017;72:12-8.

13. Abildgaard J, Pedersen AT, Green CJ, Harder-Lauridsen NM, Solomon TP, Thomsen C, et al. Menopause is associated with decreased whole-body fat oxidation during exercise. Am J Physiol Endocrinol Metab. 2013;304: E1227-36. 
14. Sutton-Tyrell K, Selzer F, Sowers MFR, Neer R, Powell L, Gold EB, et al. Study of Women's health across the nation (SWAN), 1995-1997: cross-sectional screener dataset. Ann Arbor: Inter-university consortium for political and social research [distributor]; 2018. https://doi.org/10.3886/ICPSR04368.v4.

15. Sutton-Tyrell K, Selzer F, Sowers MFR, Finkelstein J, Powell L, Gold EB, et al. Study of Women's health across the nation (SWAN), 2002-2004: visit 06 dataset. Ann Arbor: Inter-university consortium for political and social research [distributor]; 2018. https://doi.org/10.3886/ICPSR31181.v2.

16. Sutton-Tyrell K, Selzer F, Sowers MFR, Finkelstein J, Powell L, Gold EB, et al. Study of Women's health across the nation (SWAN), 2003-2005: visit 07 dataset. Ann Arbor: Inter-university consortium for political and social research [distributor]; 2018. https://doi.org/10.3886/ICPSR31901.v2.

17. Sutton-Tyrell K, Selzer F, Sowers MFR, Finkelstein J, Powell L, Gold EB, et al. Study of Women's health across the nation (SWAN), 2004-2006: visit 08 dataset. Ann Arbor: Inter-university consortium for political and social research [distributor]; 2018. https://doi.org/10.3886/ICPSR32122.v2.

18. Sutton-Tyrell K, Selzer F, Sowers MFR, Finkelstein J, Powell L, Gold EB, et al. Study of Women's health across the nation (SWAN), 2005-2007: visit 09 dataset. Ann Arbor: Inter-university Consortium for Political and Social Research [distributor]; 2018. https://doi.org/10.3886/ICPSR32721.v2.

19. Sutton-Tyrrell K, Selzer F, Sowers MFR, Finkelstein J, Powell L, Gold EB, et al, Study of Women's health across the nation (SWAN), 2006-2008: visit 10 dataset. Ann Arbor: Inter-university consortium for political and social research [distributor]; 2018f. https://doi.org/10.3886/ICPSR32961.v2.

20. Sowers MF, Crawford SL, Sternfeld B, Morganstein D, Gold EB, Greendale GA, et al. Design, survey sampling and recruitment methods of SWAN: a multi-center, multi-ethnic community-based cohort of women and the menopausal transition. In: Lobos RA, Kelsey J, editors. Menopause: biology and pathobiology. San Diego: Academic Press; 2000. p. 175-88.

21. Lukaski HC, Johnson PE, Bolonchik WW, Lykken Gl. Assessment of fat-free mass using bioelectrical impedance measurements of the human body. Am J Clin Nutr. 1985:41:810-7.

22. Boulier A, Fricker J, Thomasset AL, Apfelbaum M. Fat free mass estimation by the two-electrode impedance method. Am J Clin Nutr. 1990;52:581-5.

23. Tanaka NI, Hanawa S, Murakami H, Cao Z-B, Tanimoto M, Kiyoshi S, et al. Accuracy of segmental bioelectrical impedance analysis for predicting body composition in pre- and postmenopausal women. J Clin Densitom. 2015;18:252-9.

24. Janssen I, Heymsfield SB, Baumgartner RN, Ross R. Estimation of skeletal muscle mass by bioelectrical impedance analysis. J Appl Physiol. 2000;89: 465-71.

25. Chumlea WC, Guo SS, Kuczmarcki RJ, Flegal KM, Johnson CL, Heymsfield SB, et al. Body composition estimates from NHANES III bioelectrical impedance data. Int J Obes Relat Metab Disord. 2002:26:1596-611.

26. Gold EB, Crawford SL, Shelton JF, Tepper PG, Crandall CJ, Greendale GA, et al. Longitudinal analysis of changes in weight and waist circumference in relation to incident vasomotor symptoms: the study of Women's health across the nation (SWAN). Menopause. 2016:24:9-26.

27. Sowers MR, Jannausch M, McConnell D, Little R, Greendale GA, Finkelstein JS, et al. Hormone predictors of bone mineral density changes during the menopausal transition. J Clin Endocrinol Metab. 2006;91:1261-7.

28. Crawford SL, Avis NE, Gold E, Johnston J, Kelsey J, Santoro N, et al. Sensitivity and specificity of recalled vasomotor symptoms in a multiethnic cohort. Am J Epidemiol. 2008;168:1452-9.

29. Gold EB, Colvin A, Avis N, Bromberger J, Greendale GA, Sternfeld B, et al. Longitudinal analysis of the association between vasomotor symptoms and race/ethnicity across the menopausal transition: study of Women's health across the nation. Am J Public Health. 2006;96:1226-35.

30. Thurston RC, Chang Y, Mancuso P, Matthews KA. Adipokines, adiposity, and vasomotor symptoms during the menopause transition: findings from the study of Women's health across the nation. Fertil Steril. 2013;100:793-800.

31. Waetjen LE, Johnson WO, Xing G, Feng WY, Greendale GA, Gold EB. Study of Women's health across the nation: serum estradiol levels are not associated with urinary incontinence in midlife women transitioning through menopause. Menopause. 2011;18:1283-90.

32. Da Fonseca AM, Bagnoli VR, Souza MA, Azevedo RS. De Barros Couto junior E, Soares junior JM et al. impact of age and body mass on the intensity of menopausal symptoms in 5968 Brazilian women. Gynecol Endocrinol. 2013; 29:116-8.

33. Gallichio L, Miller SR, Kiefer J, Greene T, Zacur HA, Flaws JA. Change in body mass index, weight, and hot flashes: a longitudinal analysis from the midlife women's health study. J Women's Health. 2014;23:3.
34. Gjelsvik B, Rosvold EO, Dalen I, Hunskaar S. Symptom prevalence during menopause and factors associated with symptoms and menopausal age: results from the Norwegian Hoardland Women's cohort. Maturitas. 2011;70: 383-90.

35. Herber-Gast G-CM, Mishra GD, van der Schouw YT, Brown WJ, Dobson AJ. Risk factors for night sweats and hot flushes in midlife: results from a prospective cohort study. Menopause. 2013;20:953-9.

36. Kazlauskaite R, Innola P, Karavolos K, Dugan SA, Avery EF, et al. Abdominal adiposity changes in white and black midlife women: the study of Women's health across the nation. Obesity. 2015;23:2340-3.

37. Akindele $\mathrm{MO}$, Phillips JS, Igumbor EU. The relationship between bodyfat percentage and body mass index in overweight and obese individuals in an urban African setting. J Public Health Afr. 2016;7:515.

38. Zhou Y, Zheng Y, Li C, Hu J, Zhou Y, Geng L, et al. Association of body composition with menopausal symptoms in (peri-)menopausal women. Climacteric. 2018;21:179-83.

39. Sánchez-Rodriguez MA, Zacarías-Flores M, Arronte-Rosales A, Correa-Muñoz E, Mendoza-Núñez VM. Menopause as risk factor for oxidative stress. Menopause. 2012;19:361-7.

40. Zacarías-Flores M, Sánchez-Rodríguez MA, García-Anaya OD, Correa-Muñoz E, Mendoza-Núñez VM. Relationship between oxidative stress and muscle loss in early postmenopause: an exploratory study. Endocrinol Diabetes Nutr. 2018;65:328-34.

41. Cagnacci A, Palma F, Romani C, Xhouli A, Bellafronte M, Di Carlo C. Are climacteric symptoms associated with risk factors of cardiovascular disease in per-menopausal women. Gynecol Endocrinol. 2015;31:359-62.

\section{Publisher's Note}

Springer Nature remains neutral with regard to jurisdictional claims in published maps and institutional affiliations.

Ready to submit your research? Choose BMC and benefit from:

- fast, convenient online submission

- thorough peer review by experienced researchers in your field

- rapid publication on acceptance

- support for research data, including large and complex data types

- gold Open Access which fosters wider collaboration and increased citations

- maximum visibility for your research: over $100 \mathrm{M}$ website views per year

At $\mathrm{BMC}$, research is always in progress.

Learn more biomedcentral.com/submissions 